\title{
Endocrine Disruptors: \\ An Evolving Health Concern in International Organizations
}

\author{
Iris Borowy
}

\section{Introduction}

$\mathrm{I}$ a complicated world full of risks that appear especially menacing for often being invisible, indirect and difficult to assess for the non-expert, people need experts to give them credible advice on the extent and the nature of risks and on reasonable ways to react. In the twentieth century risk assessment has become an integral component of political and public life. ${ }^{1}$ In a complicated world full of experts, who often come to different conclusions using different methods and different criteria of evaluation, people need credible recommendations based on authoritative analysis of existing expertise. International organizations, supposedly standing above special national interests, are expected to act as experts of the experts. In more detailed terms this role has been described as defining concerns and framing questions for research, offering a forum for communication between experts and stakeholders, establishing state of the art understanding of an issue at hand and, as far as possible, creating consensus about it, and providing guidelines for suitable corrective and preventive action. ${ }^{2}$ By all means this is a tall order. Faced with incomplete and often contradictory knowledge, international organizations have to strike a balance between too much and too little caution. They also have to manoeuver between vested interests as well as between the contradictory demands of science and politics, requiring on the one hand, scientific precision, using cautious language and providing adequate representation of doubts, and, on the other hand,

1 Ulrich Beck, Risikogesellschaft (Berlin: Suhrkamp, 1986).

2 Michael Barnett and Martha Finnemore, "The Politics, Power, and Pathologies of International Organizations", International Organization, 53: 4 (1999), 699-732; Per-Olof Busch, 'The OECD Environment Directorate. The Art of Persuasion and its Limitations", Working Paper 20, The Gobal Governance Project, (2006). http://www.glogov.org/images/doc/wp20.pdf; Ernst Haas, When Knowledge is Power. Three Models of Change in International Organizations (Berkeley, 1990); 
unequivocal statements, which are sufficiently clear to be useful for policy recommendation.

Expectations are especially strong and began particularly early with regard to health. The need for international decisions on what did or did not constitute health threats and what to do about it can be seen as the origin of international health cooperation, and it was accepted by international health organizations (IHOs) early on. ${ }^{3}$ From the outset in 1946 the World Health Organization (WHO) has been expected to promote and conduct research in the field of health ... to provide information, counsel and assistance in the field of health' and 'to assist in developing an informed public opinion among all peoples on matters of health'. ${ }^{4}$ Several other organizations have also come to issue verdicts on health-related issues, due to the proliferation of public and private organizations engaged in international health since the 1980s and to the multidisciplinary nature of health and its interaction with a broad range of social determinants. Complicated health issues that have no clear or simple cause-effect relation and touch on the responsibilities of several institutions present a special challenge for IHOs. This paper addresses one particularly complicated issue.

Endocrine disrupting chemicals (EDCs) are compounds believed to bring the endocrine system of living beings, including humans, into disorder by mimicking hormones. The endocrine system manages central processes in living organisms including growth, metabolism and reproduction. During fetal development hormones set the 'program' for development of the growing being from birth to maturity so that their influence during gestation may only become visible many years later. It is a complex system, affected by numerous interacting elements, which evade simple cause-effect relations and fall into the areas of expertise of scientists that do not often talk to, let alone cooperate with, one another. The effects of a growing list of substances with possible endocrine disrupting qualities on human health have been the object of discussions and controversy since the 1990s. This list includes numerous substances that had already caused concern before, at a time before there were EDCs.

For scholars of international health EDCs present a fascinating case study since they allow observing in real time how various stake holders negotiate a growing body of data from the first detection of a possible threat to evolving discussions, while possible assessments of its risk range between non-existent to dramatic. The story falls into two distinct periods: a first in which the conditions were set that both facilitated and obstructed the understanding of EDCs, and a second, in which the concept and scale of EDCs were debated. The second phase is far from over. This

3 Neville M. Goodman, International Health Organizations And Their Work, (Edinburgh / London, 1952, 2nd extended edition 1971), pp. 46-71; Iris Borowy, Coming to Terms with World Health (Berlin, 2009).

4 Constitution of the World Health Organization, art. 2, 22 July 1946, http://apps.who.int/gb/bd/PDF/bd47/EN/constitution-en.pdf, consulted 23 Jan 2014. 
paper aims to be an early effort at disentangling the various actors and their concepts which have shaped the response of IHOs to the challenge of EDCs.

\section{From the 1970s to the 1990s: IHO health work before EDCs}

The two most spectacular examples of EDCs, so far, erupted long before this expression existed. Thalidomide was first sold as a sedative by the German pharmaceutical company Chemie Grünenthal in 1957 and was subsequently marketed under approximately sixty trade names in many countries for numerous illnesses, ranging from insomnia and morning sickness to depression, premature ejaculation, tuberculosis, premenstrual symptoms, menopause, stress headaches, alcoholism, anxiety, and emotional instability. After some years doctors noticed a rising number of infants born with congenital deformations to mothers who had taken the drug during pregnancy. In December 1961 an article by the Australian doctor William McBride appeared in Lancet and Hamburg medical professor Widukind Lenz publicized his findings about a correlation in Germany, and by the end of the year the drug had been withdrawn from the market in most countries. More than ten thousand children worldwide are believed to have been born with deformed or missing limbs because of the effects of the drug. A large-scale court case against Grünenthal ended in 1970 with a dismissal of the case after a donation by the company to an assistance fund for victims.

The number of affected people and the severity of the deformations made Thalidomide an outstanding case of teratogenic damage, but its impact was limited by its relatively direct connection between cause and effect, since abnormalities were immediately visible at birth. By comparison the case of diethylstilbestrol (DES), a synthetic estrogenic substance, remarkably similar to natural female hormones, was more difficult to establish. Despite early indications of carcinogenic and teratogenic effects in animal tests and an initial rejection of admission in the USA, the drug was accepted for sale in the 1940s, and subsequently millions of women were prescribed DES as therapy during menopause and to prevent miscarriages during pregnancies. Many more people took in smaller quantities through their food when DES was fed to lifestock to accelerate weight gain. In 1971 doctors began to note clusters of rare vaginal cancers in women whose mothers had taken DES during pregnancy. By 2008 it appeared that of 'the 2 million to 5 million children who were exposed to DES prenatally, nearly 95 percent of them have experienced reproductive tract problems,

5 Jerry Avorn, "Learning about the Safety of Drugs - A Half-Century of Evolution", New England Journal of Medicine, 365 (2011), 2151-2153; Carsten Timmermann, "Die Nachtseite des Wirtschaftswunders", FAZ, 25 Nov 2001, http:/www.k-faktor.com/contergan/artikel8.htm, consulted 27 Jan 2014. 
including menstrual irregularities, infertility, and higher risks of a variety of reproductive cancers. ${ }^{6}$

These two cases established two principles of the future discussions on EDCs: that a substance, which caused no harm to adults, could affect the development of the fetus, including in ways which might only become apparent decades later when the former fetus had reached adulthood, and that its effect did not follow a classical toxicological dose-response mechanism.

Both scandals were viewed as medical and pharmaceutical issues, and the World Health Organization (WHO) was the only IHO that reacted. The thalidomide disaster triggered the establishment of the WHO International Drug Monitoring Programme. First preparations began in 1962 and a pilot project with ten member countries ran from 1968 to 1971, when the program became permanent. It proceeded to grow rapidly and to issue policy guidelines, general publications and safety reviews of specific medicines, acting in response to national reports. In 1968, the Pilot project received 5645 drug reaction reports from ten countries. In 2008, the programme declared having some four million case reports from approximately 100 countries. ${ }^{7}$ It formed a model case of an $\mathrm{IHO}$ providing information and guidance on a perceived health threat.

These challenges were constructed as strictly iatrogenic risks, i.e. as a function of monitoring medical drugs. For a long time, few people saw a relation to environmental and occupational hazards related to the explosive growth of the chemical industry. The global production of chemical products surged from 1.5 million tons in 1950 to 50 million tons in 1976 and 100 million tons in 1989. In 2006, it would amount to 246 million tons, still growing. ${ }^{8}$ Large part of chemicals went into the production of plastics whose very plasticity made them useful for a sheer endless number of uses at little cost, ranging from packaging to hospital tubes and car parts. Plastic increased the sensation of growing affluence because it 'promised abundance on the cheap." But chemicals also became a substantial part of everyday life as pesticides, cosmetics, packaging, glues, clothes, electronic equipment, food additives and for countless other purposes. It soon became clear that chemicals could represent health risks during production, usage and through their virtually ubiquitous presence in food, clothes, housing etc. and as waste after having been discarded. Therefore substances which, some decades later, would be considered EDCs first gained attention as occupational or environmental health hazards.

6 Nancy Langston, "The Retreat from Precaution. Regulating Diethylstilbestrol (DES), Endocrine Disruptors and Envirornmental Health", Environmental History, 13 (2008), 41-65, 51.

7 Jan Venulet1 and Margaretha Helling-Borda, "WHO's International Drug Monitoring - The Formative Years, 1968-1975”, Drug Saf, 33: 7 (2010), e1-e23.

8 http://www.chemgapedia.de/vsengine/media/vsc/de/ch/16/schulmaterial/mac/alltag/ grafik/weltproduktion kunststoffe.jpg, consulted 20 Jan 2014.

9 Susan Freinkel, Plastic. A Toxic Love Story, Boston: Houghton Mifflin, 2011, 7. 
One of the most notorious and most researched examples involves polychlorinated biphenyls (PCBs). PCBs had been commercially produced since the late 1920s, and it had since been applied in plasticizers, surface coatings, inks, adhesives, flame retardants, pesticide extenders and paints. ${ }^{10}$ During the 1920 s and 1930 s, workers in manufacturing plants repeatedly suffered severe, sometimes fatal chloracne. PCBs also emerged as agents of food poisoning in 1968, when 1,300 residents of Kyushu, Japan, became ill after eating rice-bran oil, which had been contaminated with PCB fluids. Fifty people died. ${ }^{11}$ Meanwhile, Rachel Carson's Silent Spring regarding the consequences of massive use of pesticides in agriculture on birds, published in 1962, established chemicals such as DDT as an environmental rather than a health problem. ${ }^{12}$

IHOs got involved in discussions regarding chemical safety early on and with a rapidly growing number of programs. The International Labour Office (ILO) regularly addressed hazards of toxic substances as an issue of occupational health issues already during the 1920 and 1930s. ${ }^{13}$ After 1945 the ILO, the Food and Agriculture Organization (FAO) and the WHO, individually and jointly, addressed health repercussions of chemicals. The early focus was on pesticides. Prompted by a 1951 World Health Assembly resolution the WHO presented its first report in 1953. It concluded that, when properly used, existing pesticides did not appear to cause imminent health threats, though long-term effects or consequences of new substances needed to be observed. This finding was largely confirmed three years later by a joint ILO-FAO-WHO study group. Their report revealed their profoundly ambivalent view of pesticides: while it was acknowledged that pesticides might, under certain circumstances, present some risks and that it was preferable not to have any residues in milk or water, this was not always possible since the use of pesticides was found indispensable for several purposes such as the production and storage of food and for the fight against vector-borne diseases, notably malaria. ${ }^{14}$ This view characterized the position both of joint FAO/WHO and ILO/WHO expert committees on pesticides throughout the $1960 \mathrm{~s}^{15}$ An $\mathrm{FAO} / \mathrm{WHO}$ meeting in 1963 resulted in a report that

10 IPCS, Concise International Chemical Assessment Document 55, Polychlorinated Biphenyls: Human Health Aspects (Geneva, 2003), p. 4.

11 The History of PCBs, http://www.foxriverwatch.com/monsanto2a pcb pcbs.html, consulted 20 Jan 2014; IPCS, Polychlorinated biphenyls and terphenyls. Environmental Health Criteria 2 (Geneva, 1976); Eric Francis, "Conspiracy of Silence", Sierra, (September/October 1994) bttp://www.sierraclub.org/sierrai200103/conspiracy.asp, consulted 20 Jan 2014.

12 Rachel Carson, Silent Spring (Boston, 1962).

13 Aage Grut, "The Work of the International Labour Organization in Occupational Health", British Journal of Industrial Medicine, 8 (1951), 199-205.

14 WHO, Toxic Hazards of Pesticides to Man. Technical Report Series 114 (Geneva, 1956).

15 WHO, Principles Governing, Consumer Safety in Relation to Pesticide Residues. Technical Report Series 240 (WHO: 1962); Kingsley Kay, "Organization of Occupational Health Services for Personnel Exposed to Toxic Pesticides”, Ann. Occup. Hyg., 7 (1964), 285-297. 
addressed 37 pesticides and suggested acceptable daily intakes of fifteen of them (which earlier reports had refused to do). Further meetings expanded this list and specified which fruit, vegetables and cereals the recommendations referred to. ${ }^{16}$

Inadvertently, this act of setting standards affected not only domestic health regulations but also questions of international trade. Here, international assessments of chemical safety could help harmonize national health and trade interests if international standards were similar to national standards, and they could do substantial harm if they differed materially in either direction. This connection provoked the involvement of the Organization for Economic Cooperation and Development (OECD), an agency designed to promote economic growth and prosperity through trade in undistorted markets. In 1966 it organized a workshop on 'unintended occurrences of pesticides in the environment,' to which the OECD invited the $\mathrm{WHO}$ to send a representative. ${ }^{17}$ The meeting started a three-year project. ${ }^{18}$ Its final report made clear that the issue required more institutionalized long-term attention, and in 1971, the OECD created a long-term Sector Group on Unintended Occurrence of Chemicals in the Environment. This program aimed at the harmonization of testing methods and regulations and at ways to reduce related costs. The main driving force was the US government, which wanted to prevent European countries from using health concerns as trade barriers against the newer and more dynamic US chemical industry. ${ }^{19}$

The scenery became even more complex when, in 1972, the UN Conference on the Human Environment in Stockholm raised the international awareness of environmental concerns, including possible health effects of chemicals. As a results, the UN Environment Programme (UNEP) emerged as additional actor and the WHO initiated an Environmental Health Criteria (EHC) Programme, designed, among other tasks, to assess information on the relationship between exposure to environmental pollutants and human health, to identify gaps in pertinent knowledge, to provide guidelines for setting exposure limits and for toxicological and epidemiological methods in order to make research results internationally comparable. The first EHC report appeared in 1976, published, like its successors,

16 WHO, Pesticide Residues in Fooa, Technical Report Series No. 370 / FAO Agricultural Studies No. 73 (Geneva, 1967); WHO Pesticide Residues, WHO Technical Report Series No. 391 / FAO Meeting Report P: 1967/M/11 (Geneva, 1968). Following reports see http://www.who.int/ foodsafety/chem/jmpr/publications/reports/en/index.html, consulted 25 Jan 2014.

17 De Groot van Embden to Candau, 19 April 1966, H II/80/2 (A), WHO archive (WHOA).

18 Timmons to Candau, 29 Oct 1970, H II/80/2 (A), WHO archive (WHOA).

19 Peter Carroll and Aynsley Kellow, The OECD. A Study of Organizational Adaptation (Cheltenham, 2011), pp. 220-226. 
under joint WHO/UNEP sponsorship. ${ }^{20}$ Health concerns focused on cancer and possible damage to the liver and kidneys. The approach was solidly toxicological. Following the principle that the dose makes the poison, the assumption was that there was a threshold below which exposure to a substance was harmless and that, therefore, the task of an IHO was to provide authoritative information about what this threshold appeared to be and how pertinent studies should be conducted.

In 1974, the WHO established a study group on health hazards from new environmental pollutants. Reviewing information from toxicological data banks, clinical and laboratory work etc. it extended substantially the range of relevant chemicals to be considered, including plastics and plasticizers, fire retardants, metals, photosensitizers and pesticides. As a new feature, a draft on the harmonization of toxicological testing techniques mentioned, among others, risks of teratogenesis. ${ }^{21} \mathrm{~A}$ 1977 resolution of the World Health Assembly further broadened the perspective. In view of the ubiquitous 'growing use of chemicals' it called for studies on the problem and possible long-term strategies regarding 'the acute and especially the chronic or combined toxic effects, not only on present but on future generations, that may result from exposure to chemicals in air, water, food, consumer products and at the place of work, particularly if combined with exposure to other chemicals, infectious agents and physical factors. ${ }^{22}$ Thus, the WHO clearly advanced the approach on the issue from that of mono-substance oriented short-term effects to long-term and multisubstance considerations, including effects on future generations, aspects, which would be crucial to the ECD discourse.

However, this was only one side of what remained an ambivalent and partly contradictory position of the WHO. Chemicals formed part of environmental health, and in the general WHO context, environmental health overwhelmingly referred to risks emanating from natural and organic sources such as infections resulting from bacterial contamination of water or from disease vectors. This perspective saw industrialization and chemicals as a solution rather than as a problem. Tellingly, in late 1969, Director General Candau regarded the upcoming Stockholm Conference on the Human Environment with suspicion, lest emotions on insecticides would obstruct WHO anti-malaria work. ${ }^{23}$ In 1972, the WHO Bulletin published a study which demonstrated high levels of chlorinated pesticides, especially

20 WHO/UNEP, Mercury, EHC 1 (Geneva, 1976); WHO Task Group on Environmental Criteria for Carbon Tetrachloride, Published under the joint sponsorship of UNEP, ILO, WHO (Geneva, 1999), ix.

21 Socrates Litsios (WHO), The Third Ten Years of the World Health Organization, 19681977, (Geneva, 2008), pp. 264-266.

22 WHA30.47 Evaluation of the effects of chemicals on health, 19 May 1977, Handb. Res., Vol. II (2nd ed.), 1.11.3, http://apps.who.int/iris/bitstream/10665/93210/1/WHA30.47 eng.pdf, consulted 25 Jan 2014.

23 Note for the file, Conference on the Human Environment - 1972, 5 Dec 1969, $\mathrm{H} / \mathrm{II} / 86 / 3$, WHO archive. 
DDT, in the fatty tissues of people living in the Ferrara region, without even mentioning possible health repercussions. ${ }^{24}$ And as late as 1988, the WHO representative, who interviewed future Director General Gro Harlem Brundtland about the publication of the Commission carrying her name, wondered if the report had not concentrated too much on man-made environmental problems 'while in reality two-thirds of mankind were struggling against adverse natural conditions such as unsafe water, disease vectors, unfavourable climatic conditions, and so on. ${ }^{25}$ This perspective of health hazards of chemicals as a pet complaint of the privileged rich and a potential impediment to satisfying the health needs of the poor would continue to burden considerations at the $\mathrm{WHO}$ and may explain why different $\mathrm{WHO}$ departments could take tangibly different positions on the assessment of the health hazards of chemicals. Depending on their overall field of work, WHO staff could interpret their task either as highlighting the health risks of chemicals in order to protect populations from potential resulting health burdens, or as downplaying possible health risks of chemicals in order to prevent populations from losing crucial protection against existing health burdens.

This ambivalence showed in the second EHC paper, published in 1976, which reviewed available data in original scientific publications and national overviews on exposure levels and possible effects of PCBs and polychlorinated terphenyls on humans and on the environment. The paper clearly outline the extent of human exposure to the substance, estimating that the cumulative world production of PCBs since 1930 were about one million tons, about half of which were found in dumps and landfills from which they were slowly being released. They were well absorbed by mammals through the gastrointestinal tract, lungs, and skin, stored mainly in adipose tissue, and they passed the placental barrier. Most people tested, had shown PCB levels up to $1 \mathrm{mg} / \mathrm{kg}$ body weight, though exposure, notably in work places, could be much higher. But the authors of the text were not overly alarmed by these findings. Man appeared to be the species most sensitive to PCB, and the contamination incident in Japan had suggested that $0.5 \mathrm{~g}$ (i.e. $500 \mathrm{mg}$ ) over 120 days represented the smallest dose to produce an effect. ${ }^{26}$ These data suggested that, irrespective of their massive environmental presence, $\mathrm{PCBs}$ represented little danger to health, and the paper did not provide any policy recommendation.

The attitude contrasted with the precautionary approach taken by a WHO study group at the same time as well by the OECD three years earlier. Invoking the confirmed presence of PCBs in wildlife in many countries, the OECD had called for

24 L. Prati, R. Pavenello and F. Ghezzo, "Storage of chlorinated pesticides in human organs and tissues in Ferrara Province, Italy", Bulletin World Health Organization, 46 (1972), 363-369.

25 Forum Interview with Gro Harlem Brundtland, 'Planet Earth - suicide or survival?', World Health Forum vol. 9, 1988, 180

26 IPCS, Polychlorinated biphenyls and terphenyls. EHC 2, Geneva: WHO, 1976.

http://www.inchem.org/documents/ehc/ehc/ehc002.htm\#PartNumber:9, retrieved 4 Dec 2012. 
the international control of PCBs with a goal to minimize and - eventually eliminate their escape into the environment. ${ }^{27}$ This recommendation was in line with US policy of the time, which had severely restricted the use of PCBs through the Toxic Substances Control Act of 1976 (four years after DDT) and banned its production in 1979. European countries followed suit. ${ }^{28}$ A WHO Technical Report, also published in 1976, went even further. The meta-study considered a substantially expanded spectrum of possible health risks, reviewing various methods to test mutagenicity, carcinogenicity, teratogenicity and ecological damage. Given the diffuse nature of these effects and the difficulties of experimentation with humans, warning signs were statistical and inherently problematic, since they required extensive and reliable registration of physical burdens and defects and had to consider numerous new synthetic substances in all fields of life. The concluding recommendations were bold: the introduction of new materials should not be permitted until their adverse effects, if any, had been adequately assessed. ${ }^{29}$ It was the most far-reaching demand with the most unequivocal endorsement of the precautionary principle voiced by an international organization, not paralleled before or later. It was the year when the Icmesa chemical plant, a subsidiary of Hoffman-La Roche, released large amounts of highly toxic tetrachlorodibenzodioxin into the environment at Seveso, Italy, injuring hundreds of people. ${ }^{30}$ Chemicals were increasingly recognized as potentially serious health threats.

Shortly afterwards, the chemical industry got organized to present their perspective. The European Chemical Industry Ecology and Toxicology Centre was founded in 1978, an agency financed by the who's who of chemical companies, including BASF, Bayer, Shell, ExxonMobil, Honeywell, Procter \& Gamble, Merck and others. On its 2014 website, it describes its task as

developing and promoting top quality science in human and environmental risk assessment of chemicals' and presents itself as the scientific forum where member company experts meet and co-operate with government and academic scientists, to evaluate and assess the available data, identify gaps in knowledge and recommend

$27 \mathrm{C}(73) 1$ (Final), cited in Draft Decision Recommendation of the Council on Further Measures for the Protection of the Environment by Control of Polychlorinated Bisphenyls ENV(86)22, 19 Nov 1986, OECD archive, 7.

28 Theo Colborn, Dianne Dumanoski and John Peterson Myers, Our Stolen Future (New York, 1996), p. 91. Francis, Conspiracy.

29 WHO, Health hazards from new environmental pollutants. Report of a WHO scientific group. WHO Technical Report Series, No. 586 (Geneva, 1976).

30 Pier Bertazzi et al., "The Seveso studies on early and long-term effects of dioxin exposure: a review", Environmental Health Perspectives, 106 (Supp.2) (1998), 625-633. 
research, and publish critical reviews on the ecotoxicology and toxicology of chemicals, biomaterials and pharmaceuticals. ${ }^{31}$

Its methods of work, reports and workshops, mimicked those of academia, and by posing as a forum for international and interdisciplinary exchange of scientific knowledge, the Centre claimed the ground of IHOs. In 1994, it changed its name to European Centre for Ecotoxicology and Toxicology of Chemicals (ECETOC), dropping its ties to industry from its name and thus increasing its impression as an $\mathrm{IHO}$, in charge of providing authoritative information and recommendations. ${ }^{32}$ Apparently, organizers had decided that the best way to counter negative information coming from IHOs about chemical products was to act like IHOs and hope that some people would not tell the difference.

Meanwhile, international organizations increased their institutionalized cooperation. In 1980, the International Programme on Chemical Safety (IPCS), which had already provided an informal frame to joint WHO-UNEP publications for some time, added ILO to its participants and became firmly institutionalized. Its task was to organize and assess peer review processes to evaluate the risk to human health of (combinations of) chemicals and to develop and review methods for laboratory testing and ecological and epidemiological studies with member states. ${ }^{33}$ In the following years, the IPCS became the authoritative voice of risk assessment, issuing a series of metastudies, designed to provide state of the art knowledge about a long and growing list of chemicals, addressing their possible carcinogenic effects as well as possible damage to internal organs, skin and respiratory irritation..$^{34}$ At the same time, the OECD Chemicals Programme was renamed the Environment, Health and Safety (EHS) Programme moving closer to health-related work developing at the WHO and its cooperative organs with UNEP and ILO. ${ }^{35}$ Their expertise was acknowledged at the UN Conference on Environment and Development in Rio 1992. Agenda 21, its copious plan of action, described the problem in clear terms: 100.000 chemical substances existed, of which 1.500 represented approximately $95 \%$ of world production. Crucial data for risk assessment were missing 'even for a great number of chemicals characterized by high-

31 http://www.ecetoc.org/overview, consulted 17 Jan 2014.

32 Timeline, http://www.ecetoc.org/history, consulted 17 Jan 2014.

33 WHO, WHO Task Group on Environmental Health Criteria for Carbon Tetrachloride, (Geneva, 1999), ii; WHO: Action for Environmental Health. WHO Says (Geneva, 1988), p. 16.

34 See e.g. IPCS studies on Beryllium (1990), on Alpha- and beta- hexachlorocyclohexanes (1992), on Hexachlorocyclopentadiene (1991).

35 OECD, The OECD Environment, Health and Safety Programme: Achievements, Strengths and Opportunities, ENV/JM(2011)17, http://search.oecd.org/officialdocuments/ displaydocumentpdf/?cote=ENV/JM(2011)17\&doclanguage=en, consulted 12 May 2012, 
volume production. ${ }^{36}$ Agenda 21, therefore, strongly underscored the urgent need for more research, calling on IPCS the OECD, FAO and the European Community (EC) in this regard. ${ }^{37}$

Thus, by 1992, several IHOs were well alerted to chemicals as potential health risks. They had an elaborate infrastructure of joint inter-agency committees in place. This background of institutional collaboration certainly helped coming to terms with the new challenge of EDCs. However, the strict conceptual separation stood in the way of easy inter-sectoral communication: toxicological principle of dose-response was established for occupational and environmental health while a bio-systemic understanding was used in iatrogenic health risks, and the two spheres hardly intersected. These circumstances formed the background for the understanding of the emerging new concept of endocrine disruption.

\section{From the 1990s to Today: IHO health work with EDCs}

During the 1980s evidence of disturbing phenomena emerged from a confusing range of seemingly unrelated contexts, ranging from laboratory experiments with uncontrollably multiplying cancer cells to fish of unclear sex caught near discharges of sewage treatment plants, and apparent increases in boys born with deformed genital organs. ${ }^{38}$ In July 1991, zoologist Theo Colborn gathered a group of interdisciplinary scientists, including wildlife biologists, endocrinologists, immunologists and toxicologists, in Wisconsin, to discuss a series of disconcerting changes in the Great Lakes area. After long discussions they discovered a common theme among the various phenomena and coined the expression of 'endocrine disruption' to mark diverse disorders related to hormone directed physiological processes. ${ }^{39}$ For the first time, a categorization of a group of diverse substances was based on the presumed type of health damages they provoked. Subsequently, Colborn co-authored a paper, published 1993, which laid out the bases of the new concept:

Convincing evidence exists that a variety of pollutants, some of which can disrupt endocrine development in wildlife and laboratory animals, is found in rain water, well water, lakes, and oceans, as well as freshwater, marine, and terrestrial food products. ... Endocrine-disrupting effects are not currently considered in assessing risks to humans, domestic animals, and wildlife. Taking into consideration what is currently known about chemicals that disrupt the endocrine system, the effects 1)

36 Agenda 21, $\$ 11$, http://habitat.igc.org/agenda21/a21-19.htm.

37 Agenda 21, $\$ 15$, http://habitat.igc.org/agenda21/a21-19.htm.

38 Colborn, Dumanoski and Myers, Our Stolen Future, pp. 122-135.

39 Freinkel, Plastic, pp. 92-93. 
may be manifested in an entirely different way, and with permanent consequences, in the early embryo, fetus, and neonate from effects as a result of exposure only in adulthood; 2) can change the course of development and potential of offspring, with the outcome depending on the specific developmental period(s) of exposure; and 3) are often delayed and thus may not be fully or obviously expressed until the offspring reaches maturity or even middle age, even though critical exposure occurred during early embryonic, fetal, or neonatal life. ${ }^{40}$

Drawing the connection to the DES case, the paper suggested a list of health disorders potentially caused by EDCs including preterm births, low birth weight, small skull circumference, cryptorchidism in infants, and cognitive, motoric, visual and behavioral deficits in children, breast and prostatic cancer and low sperm count in adults. In 1996, the book Our Stolen Future, also co-authored by Colborn, introduced the concept to the lay world. Virtually non-existent before, the use of expressions of 'endocrine disruptor' or 'endocrine disrupting' in written texts exploded within just a few years. ${ }^{41}$ It was the birth of a new health issue, and as fears of a diffuse danger especially to babies and children spread terror among young parents the need for more information was obvious. Scientists turned to the issue with a vengeance. Pubmed listed merely four papers using the keywords 'endocrine disruptors' in 1995. In 2011, there were 551. ${ }^{42}$

The news about this new type of threat was sufficiently disconcerting for governments of industrialized countries to take note. A 1996 OECD survey showed that almost all member countries had done or were preparing national reports or reviews on the question. Alarmed both by data about wildlife and by toxicological studies, all twenty-two countries, which returned the OECD questionnaire, considered EDCs candidates for regulatory or advisory activities, and half of them considered the issue a major concern. Roughly half the respondent administrations felt well informed about what constituted an 'endocrine disrupting substance' while the other half did not. The range of chemicals considered (potentially) hazardous included specific compounds as well as groups of substances as EDC suspects. The list revealed the potential scale of the challenge: phytoestrogens, PCBs and metabolites, phthalates, TBT, chlorinated hydrocarbons, chlorinated dioxins, alkylphenols, DDT and metabolites, organometals, pesticides, pharmaceuticals, food additives, bisphenol $\mathrm{A}$, brominated flame retardants, optical brighteners, detergent

40 Theo Colborn, Frederick S. vom Saal and Ana Soto, "Developmental effects of endocrine-disrupting chemicals in wildlife and humans", Environmental Health Perspectives, 101: 5 (1993), 378-84.

41 https://books.google.com/ngrams/graph?content=endocrine+disruptor $\% 2 \mathrm{C}+$ endocrine + disrupting \&year start $=1800$ \&year end $=2000 \&$ corpus $=15 \&$ smoothing $=3 \&$ shar e= $\&$ direct $\mathrm{url}=\mathrm{t} 1 \% 3 \mathrm{~B} \% 2 \mathrm{C}$-ndocrine $\% 20$ disruptor $\% 3 \mathrm{~B} \% 2 \mathrm{Cc} 0 \% 3 \mathrm{~B} . \mathrm{t} 1 \% 3 \mathrm{~B} \% 2 \mathrm{Cendocrine} \% 20 \mathrm{di}$ srupting $\% 3 \mathrm{~B} \% 2 \mathrm{Cc} 0$, consulted 15 Jan 2014.

42 http://www.ncbi.nlm.nih.gov/pubmed/?term=endocrine+disruptors, consulted 20 Jan 2014. 
derivatives and steroid hormones. ${ }^{43}$ If ever there was a case where IHO guidance was needed, this was one. The challenge was threefold: to assess if there were statistically significant unexplained changes in animal and human health, to determine whether these changes (if they existed) were linked to substances defined as EDCs, and to decide whether these heal th effects of EDCs (if they existed) were sufficiently serious to warrant specific policies.

IHOs reacted by recommending, commissioning and evaluating studies into the question, each taking different perspectives. Early approaches focused on wildlife, for which more data were available. In 1996 the OECD established a Special Activity on Endocrine Disrupter Testing and Assessment which initially addressed the economic repercussions of possible effects of EDCs on aquatic life due to their consequences on commercial fishing. ${ }^{44}$ The WHO was even quicker. Its $1993 \mathrm{EHC}$ update on PCBs, a fat volume of 682 pages, which reviewed the findings of over 1000 original papers and several scientific conferences since 1976, included as a new feature, a very technical chapter, specifically entitled 'effects on the endocrine system.' While this chapter dealt exclusively with observations regarding effects on animals, the final conclusions also addressed effects on experimental animals, humans and the environment. The text acknowledged the wide distribution of PCBs in the environment throughout the world, its persistence and its accumulation in food webs. Human exposure continued to be largely from the consumption of contaminated food, especially mother's milk for babies, but also from inhalation and skin absorption. But firm findings continued to be inhibited by complications: PCBs were frequently found in combination with carcinogenic polychlorinated dibenzofurans (PCDFs), which appeared to exacerbate their toxicity but also made it difficult to establish clear cause and effect chains. Thus, the conclusions of the text acknowledged the degree to which humans had become helpless victims of chemical exposure:

It is clear from available data on polychlorinated biphenyls (PCBs) and polychlorinated terphenyls (PCTs) that, in an ideal situation, it would be preferable not to have these compounds in food at any level. However, it is equally clear that the reduction of PCBs or PCTs exposure from food sources to 'zero' or to a level approaching zero, would mean the elimination (prohibition of the consumption) of

43 OECD, Summary Report of the 1996 OECD Questionnaire on Endocrine Disrupting Substances, undated, unnumbered, OECD Archive, pp. 1- 4.

44 Endocrine Disrupter Testing and Assessment, http://www.oecd.org/env/ chemicalsafetyandbiosafety/testingofchemicals/endocrinedisruptertestingandassessment.htm, retrieved 5 Dec 2012. 
large amounts of important food items, such as fish, but more importantly breast milk. ${ }^{45}$

The logic of EDCs as unpleasant but unavoidable risk repeated a similar approach regarding pesticides some forty years earlier. Accordingly, recommendations appeared mild: more research, more standardization in research, disposal of the substance only in high-performance incinerators and monitoring sea mammal populations. ${ }^{46}$

Soon after, the topic formed the subject of a remarkably broad-based conference. In late 1996, the European Centre of the WHO, the European Commission, the European Environmental Agency, the OECD and various national administrations co-organized a Workshop on the Impact of Endocrine Disruptors on Human Health and Wildlife in the English town of Weybridge, where experts in various fields pooled their knowledge. Participants were cautious regarding wildlife, where they saw 'few cases within the EU ... where effects could be clearly ascribed to endocrine disruptors,' and even more so concerning human health. They agreed that there was sufficient evidence to establish that testicular cancer rates were rising and sperm counts falling in some regions and that "existing exposure information was generally insufficient to definitely associate the human changes seen with chemical exposure.' 47 More research was therefore needed to establish if, to what extent and in what way certain chemicals might interfere with animal and human health. As an important step forward, the workshop proposed a definition of an endocrine disrupter as 'an exogenous substance that causes adverse health effects in an intact organism, or its progeny, consequent to changes in endocrine function.' 48 It was an early attempt at giving a more precise meaning to a phenomenon whose effects might be limited to wildlife and whose very existence was in doubt for humans.

This caution was understandable, because for international organizations, this new categorization of health issues was a mixed blessing. On the one hand, it provided a theory for the physiological processes in which chemical compounds might cause the rising incidence in an array of health problems, otherwise difficult to explain. But this theoretical precision made scientifically sound conclusions exceedingly complicated because it required explaining mechanism which contradicted the rules so far assumed to determine the health risks of chemicals. During the preceding

45 WHO, $\$$ 1.1.1., IPCS, Polychlorinated biphenyls and terphenyls, 2nd ed. Environmental Health Criteria 140, (Geneva, 1993). http://www.inchem.org/documents/ehc/ehc/ehc140.htm, retrieved 10 Sept 2013; see also http://apps.who.int/iris/handle/10665/38678.

46 IPCS, Polychlorinated biphenyls and terphenyls, 2nd ed. Environmental Health Criteria 140 (Geneva, 1993), http://www.inchem.org/documents/ehc/ehc/ehc140.htm, retrieved 4 Dec 2012.

47 European Workshop on the impact of endocrine disruptors on human health and wildlife. Conclusions and recommendations, 2 -4 Dec 1996. http://ec.europa.eu/environment/ chemicals/endocrine/documents/reports conclusions en.htm\#, retrieved 10 Sept 2013.

48 Ibid. 
decades the health repercussions of chemicals had been assessed in toxicological terms: the toxicity of a given substances was a function of the dose of exposure ('doseresponse'), and its specification required a reproducible relation between a causative agent and its outcome. Both principles were violated by research regarding EDCs. The concept of endocrine disruption through chemicals assumed that the effects of the substances in question did not depend primarily (or not at all) on its dose but, as with endogenous hormones, on the time and condition of exposure, on possible complex interaction with other substances and on tissue-specific effects such as receptor selectivity. Accordingly, results of exposure tests could vary widely, depending on circumstances.

Although this mechanism was well established for drugs like DES, many toxicologists were unwilling to accept it for environmental exposure. And, since experiments with humans were out of the question for ethical reasons, establishing authoritative expertise was difficult. Initially, the majority of data derived from biologists rather than medical scientists, and it was unclear to what extent findings about deformations in fish and mollusks were relevant to humans. Reliable epidemiological data, especially on long-term development of exposed individuals, were often difficult to establish and even more difficult to correlate to exposure levels regarding any specific example of a long list of chemicals with which people had been surrounded in the course of many years. Laboratory tests with animals raised the question of a suitable model while in vitro tests showed endocrine activity but were unhelpful to determine whether it was beneficial or harmful to the health of an entire organism. Thus, finding robust epidemiological data on humans and creating accepted methods for in vitro and clinical tests formed difficult and time-consuming but essential steps towards establishing reliable information on the effects of EDCs for humans.

A few weeks after the Weybridge conference, a meeting sponsored by the UNDP and the US Environmental Protection Agency (EPA), with participants from the same agencies and from numerous individual countries and of industry, demonstrated the difficulty of placing the issue in a global health context. The workshop largely confirmed the Weybridge conclusions, but participants from lowincome countries in the South pointed out that, despite some awareness of possible health hazards resulting from chemical contamination, their governments 'regarded the issue as too ill defined and esoteric to take resources away from other pressing public health problems.' 49 Understandably, from a global South perspective, the increase of testicular cancer by between two and four men per 100.000 in some Scandinavian countries hardly merited redirecting funds from illnesses which killed millions of people in their countries every year. However, the global and long-term

49 International Workshop on Endocrine Disruptors, 22-24 Jan 1997, http://www.epa.gov/edrlupvx/Pubs/smithrep.html, retrieved 10 Sept 2013. 
perspective differed: if wildlife in remote corners in different continents was affected by any given proportion of the rapidly rising number of chemicals, this hazard was ubiquitous. And if the human endocrine system was, indeed, affected by the same chemicals, this rise in cancer incidence might be just the tip of a gigantic iceberg.

The new challenge appeared to arouse a certain degree of inter-agency competition. A May 1997 WHA resolution called on the Director-General of the WHO to „take the necessary steps to reinforce WHO leadership in undertaking risk assessment' regarding chemicals to human health, and to promote and coordinate research 'on potential endocrine-related health effects of exposure to chemicals.' 50 But in reality, any far-reaching work had to be cooperative. No single agency possessed all the expertise and infrastructure of institutes and people for all fields from which information would have to be pooled: the OECD was strong in chemical testing, the UNDP in environmental information, including on wildlife, and the WHO was obviously the central body regarding human health.

During the following years, the IPCS, itself a multi-agency body, cooperated with the OECD to establish a Steering Group of renowned international experts who adopted the task of establishing the state of global knowledge on the field. The result was a major IPCS report, published under WHO auspices in 2002, which summed up the findings of data collection and research of the last years. Again, they amounted to more questions and doubts than robust findings. For instance, it cited documented correlation between some EDCs and neurological development and behaviour, but it cautioned that similar effects could also result from chemicals inducing neurotoxicity rather than endocrine action. 51 Thus, pending further research, the report was very careful to point out that, so far, there was little evidence pointing to a serious public health issue. It was difficult to draw conclusions about effects on human health from statistical data alone since they were often too patchy and too varied in experimental design to allow comparisons over time or between regions and often crucial data, notably regarding exposure during critical periods of development, were simply non-existent. Besides, the concentration and potencies of endogenous hormones was generally higher than that of exogenous chemicals, adding to complexity of interpretation. A decline of human sperm quality had been observed in several countries, but its relation to ECDs remained unclear, and metastudies were inconsistent. Similarly, connections to observed increases in deformations of male reproductive organs, to precocious puberty, impaired neurological development and immune functions and several cancers remained unclear. Testicular cancer rates in Northern Europe had begun rising at the beginning of the twentieth century before the industrial production of chemicals and, therefore, could not be explained by

50 IPCS, Global Assessment of the State-of-the-Science of Endocrine Disruptors (Geneva, 2002), p. vii.

51 Ibid., p. 3. 
EDCs alone, if at all.52 Thus, in several fields there was sufficient credible evidence to establish changes in human health to raise concern, but not enough to draw a firm connection to EDCs. Yet, as one important result, the report narrowed the definition of EDC down to a more precise form to '... an exogenous substance (or mixture) that alters function(s) of the endocrine (hormonal) system and consequently causes adverse health effects in an intact organism, or its progeny, or (sub) populations.'53 It would become the standard definition, accepted by believers as well as skeptics of the phenomenon.

As both epidemiological, laboratory and clinical research continued, though sometimes with contradictory findings, subsequent reports vacillated between different degrees of assertiveness. In 2003, an update on knowledge regarding PCBs, reconstructed the topic as a full-blown endocrine question. Though the text still pointed out the lack of unequivocal results due to the large range of possible confounding factors, it now listed an impressive list of disorders which had been observed in humans exposed to PCBs, alone or in combination with other substances, including reduced sperm mobility, slowed fetal growth and development, seriously impaired neurological functions of children such as reduced reflexes, memory capacities and IQ scores (though some deficiencies appeared to disappear later during childhood), increased incidence of cancers of the digestive system and increased susceptibility to some childhood diseases. 54 Nine years later, in a WHO report on Endocrine disruptors and child health, conclusions were expressed in more tentative terms. They confirmed that several reproductive and other endocrine disorders had reached epidemic proportions to the extent of warranting a new term of testicular dysgenesis syndrome (TDS), describing cryptorchidism, hypospadias, testicular cancer and failure of spermatogenesis, and these disorders had been linked to exposure to some EDCs in animal experimentation. But evidence was still insufficient for unequivocal conclusions. Nevertheless, as a particularly disconcerting aspect, the text repeated the possible impairment of intelligence in child development.55 Another new item emerged in an EU report of 2011, which pointed out possible effects of EDCs on globally rising diabetes and obesity rates, though, as usual, firm assessments was considered to require more research.56

ECETOC, the industrial ersatz-IHO founded in 1978, established an 'Environmental Oestrogens Task Force' but otherwise remained outside the

52 Ibid., p. 3.

53 Ibid., p. 1.

54 IPCS, CICAD 55, Polychlorinated Biphenyls: Human Health Aspects (Geneva, 2003), pp. $4-5$.

55 WHO, Endocrine disruptors and child health (Geneva, 2012).

56 Andreas Kortenkamp et al.,State of the Art Assessment of Endocrine Disruptors, 2011, http://ec.europa.eu/environment/chemicals/endocrine/pdf/sota edc final report.pdf, consulted 10 Jan 2014. 
discussions for years except for an article, published in 2000, which suggested a 'set of testing and screening tiers' which integrated natural EDCs into the picture and shifted attention away from epidemiological data.57 It became more active after the EU issued regulations in 2009, which introduced considerations of risk of endocrine disruption into its admission criteria for chemical substances.58 In response, ECETOC held two workshops and issued resulting reports which acknowledged the specific mode of action of endocrine disruption but, paradoxically, retained the idea of exposure limits. Insisting on the 'science-based' character of its recommendations it called for more nuanced classifications depending on the nature of the damage caused by EDCs and between substances of low and of higher concern, depending on threshold values of potency.59 A more radical line was taken by ECETOC members in contributions to a special issue to Toxicology Letters, published online in October 2013. As a case in point, Gerhard Nohynek (long-time employee at l'Oréal) et al., sought to exonerate personal care products by raising doubts about the entire concept of EDCs. In their arguments the authors contradicted conceptual as well as epidemiological tenets of the EDCs: far higher risks should emanate from substances with much higher potency, such as hormone contraceptives or clover; non-monotonic dose-relationship contradicted centuries of pharmacological and toxicological experience; screenings showing endocrine activities triggered by a substance were irrelevant until harm to health could be demonstrated; there was no scientific evidence for some major reported disturbances like declining sperm count, increased incidence in cryptorchidism and hypospadias, nor for a link between EDCs and increasing testicular cancer rates nor for synergistic effects of several substances. Indeed, the paper flatly denied that any link had been shown between a man-made EDC which posed 'an identifiable, measurable risk to human health' adding, somewhat disingenuously, that 'the adverse effects of iatrogenic DES were long known before the endocrine disruptor was coined.'60 Derisively, Nohynek et al. commented that 'the hypothesis that the negligible exposure of humans to chemicals of negligible hormonal potency could have an effect on human fertility is absurd defying a scientific basis as well as common sense' and suggested vested interests of scientists working in the field, political correctness, a bias against everything man-

57 Tom Hutchinson et al., "Ecological risk assessment of endocrine disrupters", Environmental health perspectives, 108:11 (2000), 1007-1014.

58 European Union, Regulation (EC) No. $1107 / 2009$ of the European Parliament and of the Countil of 21 October 2009, Official Journal of the European Union, 24 Nov 2009, L 309/1309/50, $\quad$ http://eur-lex.europa.eu/LexUriServ/LexUriServ.do?uri=OJ:L:2009:309:0001: 0050:EN:PDF, consulted 29 Jan 2014.

59 Remi Bars et al., "Risk assessment of endocrine active chemicals: Identifying chemicals of regulatory concern", Regulatory Toxicology and Pharmacology, 64:1 (2012), 143-154. http://www.sciencedirect.com/science/article/pii/S0273230012001237

60 Gerhard Nohynek et al., "Endocrine disruption: Fact or urban legend?" Toxicology Letters, 223 (2013), 295-305, 301. 
made and the excessive sensitivity of male scientists to news about deformations of reproductive organs in male infants as reasons for the emergence of such an unfounded theory.61 Though the authors contrasted this apparent lack of evidence to the demonstrable relation between smoking and cancer, the strategy of creating doubt by denying or ignoring evidence and by smearing scientists in academia appeared eerily reminiscent of that used by the tobacco industry some decades earlier.62

Such vehement repudiation of the idea of EDCs may have been prompted by the rising evidence in its favor. In 2013, an expert commissioned by UNEP and WHO, published an update on the 2002 report on the state of knowledge on the topic. While still cautious, it presented the issue in much firmer and also more urgent terms.63 While approximately 800 chemicals were known or suspected of interfering with hormone receptors, only a small fraction were tested, and human exposure, especially to interacting combinations of chemicals, was now believed to be substantially higher than formerly assumed. The report qualified as strong evidence the link of some EDCs to non-descended testes in young boys, to breast cancer, prostate cancer and, somewhat less firm evidence to attention deficit/hyperactivity disorder (ADHD), cognitive and behavioral deficits and to decreased bone mineral density, and still insufficient evidence regarding adverse pregnancy outcomes, ovarian and testicular cancer, reduced semen in adult men, early puberty, diabetes and obesity.64 The report also underscored in clear terms that EDCs represented a 'special form of toxicity' which showed non-linear dose-response curves and depended on a variety of circumstantial factors. Refuting earlier perspectives of EDCs as pet health concerns of rich people, the report underscored the global relevance of the issue by relating it to international commitments to protecting vulnerable populations in the Millennium Development Goals. Despite a necessary attention to traditional environmental health risks such as malnutrition and infectious diseases emerging issues 'should be prevented from becoming future tradition environmental threats.' 65 Underscoring the ubiquity and urgency of the issue, the report flatly stated:

Endocrine disruption is no longer limited to estrogenic, androgenic and thyroid pathways. Chemicals also interfere with metabolism, fat storage, bone development and the immune system, and this suggests that all endocrine systems can and will be affected by EDCs. ... It is plausible that chemical exposure in pregnancy will affect

61 Quote ibid., 299.

62 Naomi Oreskes and Michael Conway, Merchants of Doubt (New York, 2010).

$63 \mathrm{WHO} / \mathrm{UNEP}$, State of the Science of Endocrine Disrupting Chemicals - 2012 (Geneva, 2013), pp. vii-viii.

64 Ibid., viii-x.

65 Ibid., iii. 
the health of several subsequent generations of people and wildlife that are not themselves exposed. ${ }^{66}$

In 2014, the European Commission endorsed the findings of a major GermanDanish study providing firm evidence of EDC interference with human sperm function and began a review of its policy on EDCs. ${ }^{67}$ Similarly, a 2014 report on the European Division of $\mathrm{WHO}$, reported the phenomenon of EDCs as a fact, though with varying degrees of certainty regarding different health disorders. Building on the 2012 WHO report, it bolstered its position on cases of perceived certainty and extended the list of suspected health effects, citing growing evidence that EDCs might 'play a role in the development of chronic diseases (including hormone-related cancers, obesity, diabetes and cardiovascular disease)', all of which were rising concerns of the global burden of disease. ${ }^{68}$ Within twenty years, the concept of EDCs in IHOs had evolved from virtually non-existent to a serious, potentially major, threat of global health.

\section{Conclusions}

For IHOs to establish firm positions regarding EDCs required major transformations of categorization and construction of physiologically active substances. The 1970s saw a shift in the view of chemicals from indispensable and essentially ingredients of a modern and healthful life to important substances of everyday life and potential health threats. This shift was conceptually easy because it could draw on Paracelsus' toxicological principle that the does makes the poison so that supposedly it was possible to keep any substance within safe areas of usage if threshold values of safety could be identified and implemented. The main responsibility of IHO, therefore, was to define threshold values as standards of chemical safety. At the same time, a different paradigm was in use for drug safety, which took into account potential longterm mutagenic and teratogenic effects of drugs. Here, safety considerations by IHOs (as well of by national bodies) focused on comprehensive drug testing. Medical drugs were perceived as part of a distinctly defined sphere of medicine and pharmacology, clearly within the field of competence of the WHO. Chemicals, by contrast, were important in industrial production, agriculture, international trade, environment and health, touching on the responsibilities of various organizations, all of which became active in the area.

66 Ibid., XV and 15.

67 SH/HR Max Planck Society, "Endocrine disruptors impair human sperm function", http://www.mpg.de/8201201/chemicals-fertility, accessed 6 Aug 2014.

68 WHO Europe, Identification of risks from exposure to Endocrine-Disrupting Chemicals at the country levels (Copenhagen, 2014), p. 17. 
Thus, when seemingly unrelated evidence of changes in the environment, wildlife and in humans was reported, different organizations with different agendas began paying attention to different aspects of the phenomenon, and making sense of emerging information required an unusual degree of inter-agency cooperation based on acknowledged inter-dependence. This process risked resembling the group of blind people who try to establish the nature of an elephant by each touching a different part of its body. But such collaboration was greatly facilitated by a preexisting tradition and infrastructure of inter-agency cooperation. Institutionally, there were a series of programs which could be put to use for the various components of ECD research notably the OECD program on chemical testing, the EHC program within the WHO, the IPCS and programs for inter-agency cooperation, all of which were prepared to assess chemical risks. Thus, being able to unite the environmental knowledge, emanating from UNEP and FAO, the laboratory expertise spurred by OECD, the experience with occupational health collected by ILO and the health competence of $\mathrm{WHO}$, formed an immense benefit in constructing a multi-faceted phenomenon. Indeed, it may be speculated that without such a well-established network of joint commissions, establishing the state of existing knowledge on an international level would have been considerably slower.

But for all agencies, creating this new paradigm required reconstructing the views of chemical substances, including those in which work had been done for many years, shifting attention from toxic qualities to biomedical interference. This process was burdened by the rapidly increasing presence of the substances of concern to near omnipresence. Depending on perspective, this growing ubiquity of chemicals made their potentially dangerous character either highly improbable or highly alarming. In any event, it complicated identifying risks from the rising level of fuzzy noise. It also opened up opportunities for industry to use the working structures and the argumentation that public IHOs had been employing so far. Thus, by using selected epidemiological and laboratory data and insisting on prior toxicological paradigms, industry, through ECETOC, tried to strengthen their efforts to discredit gradually evolving knowledge on EDCs. The question was further complicated by the fact that a lot of relevant expertise was held within the chemical industry which, in turn, had an obvious interest in playing down possible health risks. Thus, research tended to show a 'sharp division between those who report detrimental effects of ED at environmental levels (micro- to picomolar range) - mostly academic experts - and those who appear unable to do so at any concentration - industry corporations. ${ }^{39}$

The challenge for IHOs was how to react to a situation of risk uncertainty. The idea of the precautionary principle had entered WHO language many years before the words had been coined for this purpose in Rio, and for medication it was

69 André Marques-Pinto and Davide Carvalho, "Human infertility: are endocrine disruptors to blame?" Endocrine Connections, 2 (2013), R15-R29, R17. 
implemented with a strong emphasis on drug safety. For chemicals, the sheer reality of a world awash in products made from new synthetic materials made this approach impractical, despite occasional declaration to the contrary. Thus, allegiances to the precautionary principle, once writ large, receded to the background. In 1976, a WHO report had demanded that the harmless nature of chemicals be established before they were released, supposedly by manufacturers. Twenty years later, instead of demanding proof of harmlessness from chemical industry, several large international organizations assumed the responsibility of assessing the potentially harmful character of specific chemicals. This strategy was probably inevitable. Manmade material had grown too widespread to be treated according to a strict interpretation of the precautionary principle. But the attitude of IHOs was also a defeat of sorts. Instead of a general policy of industry having to prove the harmlessness of its products, the withdrawal of products from the market had required that independent scientists provide substantial evidence of risk. IHOs appear to have had little influence on these national decision making processes. However, IHOs can be credited for not shying away from stating suspected risks and making clear that careful wording resulted from an absence of evidence regarding risks rather than from evidence of their absence.

Thus, endocrine disruptors have been a global epidemic in the making, whose extent is still impossible to assess. In some ways, the situation is not unlike the first Sanitary Conferences between 1851 and the early twentieth century. The threatening diseases of the time, cholera, plague and yellow fever, may have been more easily defined than the diffuse list of potential EDC related illnesses, but otherwise the is a very similar situation of international bodies expected to provide policy recommendations in the face of scientific uncertainty. ${ }^{70}$ In both periods, negotiations on international health focused on two key areas:

1. The scientific accuracy of cause-effect theories regarding health problems;

2. The suitable balance between precaution and risk in the face of different degrees of uncertainty.

Then as now, scientific disagreement has been affected by competing disciplinary approaches. Just like the outbreak of cholera could be assessed in terms of miasma theory or in terms of contagionism, each calling for different preventive strategies, the possible relation of chemical substances to increased incidence in testicular cancer could be assessed within toxicological or bio-systemic frameworks, each leading to fundamentally different conclusions. And in both phases of international health organization (IHOs), erring on the question of risk could have serious outcomes: too

70 Norman Howard-Jones, The scientific background of the International Sanitary Conferences 1851-1938 (Geneva, 1975); Valeska Huber, "The Unification of the Globe by Disease? The International Sanitary Conferences on Cholera, 1851-1894", The Historical Journal, 49:2 (2006), 453-476. 
much caution threatened to cause enormous economic losses (through the disruption of trade and/or of production in a major economic sector), too little threatened to cause deaths (through epidemics of infectious diseases or of slowly developing illnesses). Then as now, international cooperation was essential because addressing serious health threats while maintaining trade required agreeing on scientific knowledge and sensible precautionary strategies and regulations.

It is too early for an in-depth appraisal of the role of IHOs, individually and collectively, in the evolution of EDCs as public health issues. Tentatively, it appears that, initially, instead of setting the agenda they were taken by surprise by its rapid onset. They were then simply unable to undertake the necessary massive collection of epidemiological, clinical and laboratory data themselves. Their main function has been to receive, analyze and evaluate evolving knowledge into publications that took stock of the state of the art knowledge and - tentatively - issued recommendation. Given these circumstances, they reacted quite quickly, making use of the existing infrastructure of commissions, experts and inter-agency connections and, some evidence suggests, by some degree of inter-agency rivalry. Initial evaluation of available data was very cautious, apparently more concerned about being accused of alarmism in the face of insufficient evidence than of complacency in the face of sufficient evidence of health risks.

For the WHO, a strong policy has been weakened to some extent by a NorthSouth gradient, whereby chemicals were no priority issue within its overall work program. However, this dichotomy appears to be weakening as the list of possible health effects is lengthening, increasingly including diseases like obesity or diabetes, issues of concern in high- as well as low-income countries. Increasingly, EDCs are being viewed as an issue of global concern. In 2014, 1.115 contributions to a UN crowd-sourcing platform on sustainable development from scientists around the world established a list of 96 issues they would like policy-makers to consider for action. 'Large-scale increases in genetic mutations in humans due to accumulation of toxic chemicals in our environment and in food chains' was ranked eleventh. ${ }^{71}$ If this momentum continues, findings may well become more threatening to the chemical industry and to everyday life, as we know it. Should this happen, IHO credibility for setting standards, providing recommendations and fora for broad-based stakeholder deliberations will be crucial.

Iris Borowy is Distinguished Professor in the College of Liberal Arts at Shanghai University.

71 United Nations. Prototype Global Sustainable Development Report. Online unedited edition. United Nations Department of Economic and Social Affairs, Division for Sustainable Development, 1 July 2014, 21-22, http://sustainabledevelopment.un.org/globalsdreport/, accessed 6 Aug 2014. 


\title{
References
}

\author{
Archives
}

OECD archive

WHO archive (WHOA).

\section{Published sources}

Avorn, Jerry, "Learning about the Safety of Drugs - A Halt-Century of Evolution", New England Journal of Medicine, 365 (2011), 2151-2153.

Barnett, Michael and Martha Finnemore, "The Politics, Power, and Pathologies of International Organizations”, International Organization 53: 4 (1999), 699-732.

Bars, Remi et al., "Risk assessment of endocrine active chemicals: Identifying chemicals of regulatory concern", Regulatory Toxicology and Pharmacology, 64:1 (2012), 143-154.

Ulrich Beck, Risikogesellschaft. Berlin, 1986.

Pier Bertazzi et al., "The Seveso studies on early and long-term effects of dioxin exposure: a review", Environmental Health Perspectives, 106:2, (1998), 625-633.

Iris Borowy, Coming to Terms with World Health. Berlin, 2009.

Busch, Per-Olaf, "The OECD Environment Directorate. The Art of Persuasion and its Limitations", Working Paper 20, The Global Governance Project, (2006), http://www.glogov.org/images/doc/wp20.pdf

Peter Carroll and Aynsley Kellow, The OECD. A Study of Organizational Adaptation, Cheltenham, 2011.

Rachel Carson, Silent Spring. Boston, 1962.

Clean Water Action Council "The History of PCBs", http://www.foxriverwatch.com/monsanto2a_pcb_pcbs.html

Colborn, Theo, Frederick S. vom Saal and Ana Soto, "Developmental effects of endocrinedisrupting chemicals in wildlife and humans", Environmental Health Perspectives, 101: 5 (1993), 378-84.

Theo Colborn, Dianne Dumanoski and John Peterson Myers, Our Stolen Future. New York, 1996.

Ecotec, 'Ecotec at a glance', http://www.ecetoc.org/overview

Ecotec, 'Timeline', http://www.ecetoc.org/history

European Commission, European Workshop on the impact of endocrine disruptors on human health and wildlife. Conclusions and recommendations, 2 -4 Dec 1996, http://ec.europa.eu/environment/chemicals/endocrine/documents/reports_con clusions_en.htm\# 
European Union, Regulation (EC) No. 1107/2009 of the European Parliament and of the Council of 21 October 2009, Official Joumal of the European Union, 24 Nov 2009, L 309/1-309/50.

Forum Interview with Gro Harlem Brundtland, "Planet Earth - suicide or survival?", World Health Forum, 9, (1988), 180.

Francis, Eric, "Conspiracy of Silence", Sierra, (September/October 1994) http://www.sierraclub.org/sierra/200103/conspiracy.asp.

Susan Freinkel, Plastic. A Toxic Love Story. Boston, 2011.

Neville M. Goodman, International Health Organizations And Their Work. Edinburgh, 1952.

Grut, Aage, "The Work of the International Labour Organization in Occupational Health", British Journal of Industrial Medicine, 8 (1951), 199-205.

Ennst Haas, When Knowledge is Power. Three Models of Change in International Organizations. Berkeley, 1990.

Norman Howard-Jones, The scientific background of the International Sanitary Conferences 1851-1938. Geneva, 1975.

Hutchinson, Tom et al., "Ecological risk assessment of endocrine disrupters", Environmental health perspectives, 108:11 (2000), 1007-1014.

IPCS, Polychlorinated biphenyls and terphenyls. Environmental Health Criteria 2. Geneva, 1976.

IPCS, Beryllium. Geneva, 1990.

IPCS, Hexachlorocyclopentadient. Geneva, 1991.

IPCS, Alpha- and beta- hexachlorocyclohexanes. Geneva, 1992.

IPCS, Polychlorinated biphenyls and terphenyls, 2nd ed. Environmental Health Criteria 140. Geneva, 1993.

IPCS, Global Assessment of the State-oj-the-Science of Endocrine Disruptors. Geneva, 2002.

IPCS, Concise International Chemical Assessment Document 55, Polychlorinated Biphenyls: Human Health Aspects. Geneva, 2003.

IPCS, CICAD 55, Polychlorinated Biphenyls: Human Health Aspects. Geneva, 2003. Kay, Kingsley, "Organization of Occupational Health Services for Personnel Exposed to Toxic Pesticides", The Annals of Occupational Hygiene, 7 (1964), 285-297.

Andreas Kortenkamp, State of the Art Assessment of Endocrine Disruptors. European Commission, 2011.

Langston, Nancy, "The Retreat from Precaution. Regulating Diethylstilbestrol (DES), Endocrine Disruptors and Environmental Health", Environmental History, 13 (2008), 41-65.

Socrates Litsios, The Third Ten Years of the World Health Organization, 1968-1977. Geneva, 2008.

Marques-Pinto, André and Davide Carvalho, "Human infertility: are endocrine disruptors to blame?" Endocrine Connections, 2 (2013), R15-R29. 
Nohynek, Gerhard et al., "Endocrine disruption: Fact or urban legend?" Toxicology Letters, 223 (2013), 295-305.

OECD, Endocrine Disrupter Testing and Assessment. http://www.who.int/global_health_histories/seminars/nairobi03.pdf, retrieved 5 Dec 2012.

Naomi Oreskes and Michael Conway, Merchants of Doubt.New York, 2010.

Prati, L., R. Pavenello and F. Ghezzo, "Storage of chlorinated pesticides in human organs and tissues in Ferrara Province, Italy", Bulletin World Health Organization, 46 (1972), 363-369.

SH/HR Max Planck Society, "Endocrine disruptors impair human sperm function", (2014), http://www.mpg.de/8201201/chemicals-fertility.

Timmermann, Carsten, "Die Nachtseite des Wirtschaftswunders", FAZ, 25 Nov 2001, http://www.k-faktor.com/contergan/artikel8.htm

US Environmental Protection Agency, International Workshop on Endocrine Disruptors, 22-24 Jan 1997, http://www.epa.gov/edrlupvx/Pubs/smithrep.html.

UN, The United Nations Conference on Environment and Development, Rio Declaration on Environment and Development, 1992.

UN, Prototype Global Sustainable Development Report. United Nations Department of Economic and Social Affairs, Division for Sustainable Development, 1 (July 2014), 21-22, http://sustainabledevelopment.un.org/globalsdreport/

Venulet, Jan and Margaretha Helling-Borda, "WHO's International Drug Monitoring - The Formative Years, 1968-1975”, Drug Saf, 33: 7 (2010), e1e23.

World Health Assembly Resolution 30.47 Evaluation of the effects of chemicals on health, (19 May 1977), Handb. Res., vol. II (2nd ed.), 1.11.3, http://apps.who.int/iris/bitstream/10665/93210/1/WHA30.47_eng.pdf

WHO, Constitution of the World Health Organization, 22 July 1946, http://apps.who.int/gb/bd/PDF/bd47/EN/constitution-en.pdf

WHO, Toxic Hazards of Pesticides to Man. Technical Report Series 114. Geneva, 1956.

WHO, Principles Governing, Consumer Safety in Relation to Pesticide Residues. Technical Report Series 240. Geneva, 1962.

WHO, Pesticide Residues in Food, Technical Report Series No. 370 / FAO Agricultural Studies No. 73. Geneva, 1967.

WHO, Pesticide Residues, WHO Technical Report Series No.391 / FAO Meeting Report P: 1967/Mi11. Geneva, 1968.

WHO, Health hazards from new environmental pollutants. Report of a WHO scientific group. WHO Technical Report Series, No. 586. Geneva, 1976.

WHO, Action for Environmental Health. WHO Says, Geneva, 1988.

WHO, Task Group on Environmental Criteria for Carbon Tetrachloride, Published under the joint sponsorship of UNEP, ILO, WHO. Geneva, 1999.

WHO, Endocrine disruptors and child health, Geneva, 2012. 
WHO Europe, Identification of risks from exposure to Endocrine-Disrupting Chemicals at the country levels. Copenhagen, 2014.

WHO/UNEP, Mercury, EHC 1. Geneva, 1976.

WHO/UNEP, State of the Science of Endocrine Disrupting Chemicals - 2012. Geneva, 2013. 